Paul, K.T., Avezaat, C.J.J., Friele, R.D., IJzermans, J.N., Bal, R.A. Organ donation as transition

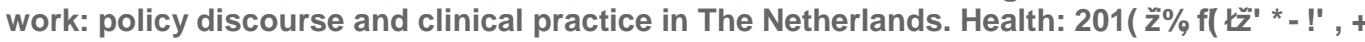

nivel

\begin{tabular}{|l|l|}
$\begin{array}{l}\text { Postprint } \\
\text { Version }\end{array}$ & 1.0 \\
\hline Journal website & http://hea.sagepub.com/content/early/2013/09/27/1363459313501357 \\
\hline Pubmed link & $\underline{\text { http://www.ncbi.nlm.nih.gov/pubmed/24084010 }}$ \\
\hline DOI & $10.1177 / 1363459313501357$
\end{tabular}

This is a NIVEL certified Post Print, more info at http://www.nivel.eu

\title{
Organ donation as transition work: Policy discourse and clinical practice in The Netherlands
}

KATHARINA T PAUL , CEES JJ AVEZAAT , ROLAND D FRIELE , JAN N IJZERMANS , ROLAND A BAL

University of Vienna, Austria

Erasmus Medical Center, The Netherlands

Netherlands Institute for Health Services Research (NIVEL) The Netherlands

Erasmus Medical Center, The Netherlands

Erasmus University Rotterdam, The Netherlands

\begin{abstract}
An increasing number of patients become eligible for organ transplants. In the Netherlands, at the level of policy discourse, growing waiting lists are often referred to as a persistent "shortage" of organs, producing a "public health crisis.” In this way, organ donation is presented as an ethical, social, and medical necessity. Likewise, policy discourse offers a range of seemingly unambiguous solutions: improving logistical infrastructure at the level of hospitals, developing organizational and legal protocols, as well as public information campaigns. Instead of taking these problem and solution definitions as given, we critically examine the relationship between policy discourse and clinical practice. Based on a historical review, first, we trace the key moments of transformation where organ donation became naturalized in Dutch policy discourse, particularly in its altruistic connotation. Second, based on in-depth interviews with medical professionals, we show how those involved in organ donation continue to struggle with the controversial nature of their clinical practice. More specifically, we highlight their use of different forms of knowledge that underlie clinicians' "transition work": from losing a patient to "gaining" a donor.
\end{abstract}

\section{INTRODUCTION}

Organ donation systems are under mounting pressure due to rapidly increasing demand for and stagnating supply of organs: More patients become identified as potential recipients as a result of obesity, excessive alcohol consumption, poorly controlled hypertension, and diabetes (Nuffield Council on Bioethics, 2011), while the number of organ donors has remained more or less stable (Jansen et al., 2010). At 
Paul, K.T., Avezaat, C.J.J., Friele, R.D., IJzermans, J.N., Bal, R.A. Organ donation as transition

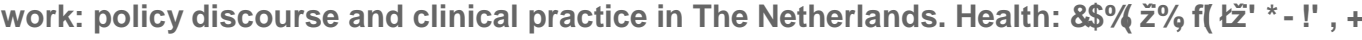

the level of policy discourse, this is often referred to as a persistent "shortage" of organs. Divergent approaches are used to address this phenomenon. In so-called opting-out systems, brain dead patients become donors by default, such as in Austria, Belgium, and Spain. Conversely, in opting-in systems, such as in the Netherlands, organ donors must either be registered in a centralized donor register or may leave the decision to their next of kin. Cross-national comparative research suggests that opting-out models do not guarantee higher donation rates (Coppen et al., 2005), suggesting a complex relation between policy and clinical practice. The Netherlands offers a primary case study for this relation as the current policy discourse addresses clinical practice through increasing efficiency and encouraging choice in the central donor register, rather than modifying legislation. In this study, we investigate the relation between policy discourse and clinical practice and ask, what kind of work and knowledge does organ donation entail and how does this work relate to contemporary policy discourse ${ }^{1}$

We begin with an account of how organ donation is shaped as an object of policy in the Netherlands. Subsequently, after a brief review of the scholarship pertaining to our study, we elaborate our conceptual and methodological approach and report on our empirical findings. We divide these into four central themes that were inductively distilled from our qualitative interview material: transition work in the consent request; managing ambiguity through protocols; patient-donor and professional transitions in intensive care units (ICUs); and evaluation and feedback mechanisms. Based on these themes, our argument is two-fold: First, we show that the transition from patient to donor cannot be pinned down in technical and temporal terms. Procedures are not as linear as often seems presumed, instead, organ donation rests on "transition work" that medical professionals engage in and are held accountable for. Second, we demonstrate that this "transition work" is managed and coordinated by a variety of actors, both medical and non-medical, and correspondingly relies on various types of knowledge: institutional, organizational, and experiential or tacit (cf. Vaughan, 2005: 48ff.). In the concluding section, we summarize our argument and conclude with some methodological reflections.

\section{TRANSPLANTATION MEDICINE AS AN OBJECT OF POLICY IN THE NETHERLANDS}

In 1968, the US-based Harvard Committee established brain stem death (BSD) as a "new" category of death (DelVecchio Good et al., 2004; Wijdicks, 2002). Brain death soon became an institutionalized feature of health care across countries, although Japan and Denmark, for instance, only recognized brain death in the early 1990s (Lock, 2002; Rix, 1990). In contrast to cardiopulmonary death, in the event of brain death, apparent breathing and respiration continue, presenting professionals and relatives with what Lock (2002) has termed a "living cadaver." We refer to this category of patient as a "donor-patient" in this article.

The socio-technical emergence of this new patient category has brought about new meanings of dying trajectories in clinical settings. It requires new kinds of patient and kin management, and new forms of organizing clinical care, with increasing professional specialization and pace of clinical activities (DelVecchio Good et al., 2004: 950ff.). Through advances in technology and pharmaceutical development, the donor-patient can now be kept stable for a longer period of time, organs can be 
screened more efficiently and effectively, and sophisticated combinations of immunosuppressant drugs alleviate rejection symptoms in the recipient.

New technologies, legal protocols, and organizational support systems developed alongside and against a constantly evolving policy discussion about "organ shortage.” At several moments, Dutch authorities considered a modification of legislation in face of the growing waiting lists: In 1969, the Dutch Red Cross proposed an opting-out system, whereas the Gezondheidsraad (Health Council) issued a similar proposal in 1975, introducing the argument of reciprocity, that is, if one was willing to potentially become an organ recipient, one would also be obliged to donate organs to others in need (Swierstra et al., 2010). While political interventions during that time period did not produce much effect, the 1990s saw a renewed interested in organ donation policies: In a period of economic growth, medical care scarcity, of which "organ shortage" was considered an element, seemed no longer socially and politically acceptable (Swierstra et al., 2010). The ensuing discourse of patient entitlement, supported by the Christian Democratic party (Christen-Democratisch Appèl, CDA), framed organ donation as a matter of solidarity (Swierstra et al., 2010).

Yet rather than introducing policy changes based on the arguments of reciprocity, patient entitlement, or scarcity in health care expressed in the 1980s and 1990s, in 1998, the Organ Donation Act (Wet Orgaandonatie) was passed. A National Donor Register was established to give citizens the opportunity to register their will on donation with four options: agreement with donation (for all or some organs and/or tissue), refusal to donation, decision left to the family, or decision left to a specific person. Efforts to promote registration at the time included direct postal invitations and campaigns by advocacy groups such as the Nierstichting (Kidney Foundation). In addition, the law made it mandatory for physicians to consult the Donor Register in case of a potential donor. Since the introduction of the law 15 years ago, and despite minor revisions in 2004, the number of deceased organ donors has fluctuated around 200 donation procedures per year (Jansen et al., 2010). This in itself, however, has been considered an achievement by commentators, in view of the decrease in traffic-related accidents and the improved care for patients with cerebrovascular accidents, the major morbidity categories for organ donors (Coppen et al., 2010).

Most recently, in 2008, the Coordination Group Organ Donation (Coordinatie Groep Orgaandonatie, CGOD) recommended a transformation of the existing opting-in system toward an Active Donor Registration system. Citizens were to receive invitations to register as donors, and should those remain unanswered, they would be included in the register by default. A written confirmation would be sent to confirm the choice, which could be reverted at any moment. The committee emphasized the notion of solidarity concerning organ donation, quality improvement in hospitals, and the need for public awareness (Coordinatie Groep Orgaandonatie, 2008). The government adopted large parts of the committee's proposals to promote organ donation and launched the Masterplan Orgaandonatie in 2009, announcing "an end to voluntarism." Considerable resources were devoted to campaigns, research, and promoting organ donation at the level of hospitals. Contrary to the CGOD's recommendation, however, the opting-in system remained intact. The present study forms part of the Masterplan, inasmuch as it is funded by the Ministry of Health and guided by the desire to "increase organ donation rates." At the same time, we seek to 
Paul, K.T., Avezaat, C.J.J., Friele, R.D., IJzermans, J.N., Bal, R.A. Organ donation as transition work: policy discourse and clinical practice in The Netherlands. Health:

move away from merely evaluative and legalistic questions; instead, we focus on the experiences of clinicians and seek to set those in relation to contemporary policy discourse. In doing so, we speak to a concern shared by sociologists and clinicians alike (Hoeyer and Jensen, 2011: 2).

\section{THEORETICAL APPROACH: LINKING POLICY AND CLINICAL PRACTICE}

To begin with, the dominant conceptualization of organ donation as a "gift of life" (Titmuss, 1970), both in academic and policy discourses, suggests a detached and depoliticizing (cf. Shaw, 2010) way of framing transplants (Healy, 2004, 2006; Mauss, 1990; Schrift, 1997; Sharp, 2006). In its appeal to the notions of solidarity and citizen-patient responsibility, this framing presumes universal validity of these concepts (see Prainsack and Buyx, 2011 for an extensive review; Streat, 2004). Conversely, sociologists and anthropologists recognize the contingency of death and dying as social categories (cf. Glaser and Strauss, 1968, Hadders, 2009; Lupton, 2003: 22ff.; cf. Kellehear, 2008; Seale, 1998; Timmermans, 2005; Timmermans and Berg, 2003: 108) and offer a conceptualization of the human body that transcends its biological features (Waldby and Mitchell, 2006). In such a vein, Lock (2002) clarifies that the conceptualization of organ donation as a "gift of life" relies on Western metaphysical distinctions between the body and the mind, a good life and a bad life, and a good death and bad death likewise. Speaking to the contingency of these distinctions, bioethical considerations regarding organ donation range from discussions on how to reconcile notions of ownership of one's organs with the notion of organ procurement as a collective good (Wight, 1991) or as "generalized altruism" (Boas, 2011). More specific issues, such as the use of financial incentives to promote organ donation, have equally been a matter of (generally inconclusive) debate (Delmonico et al., 2002).

At a lower level of analysis, medical anthropologists explore how organ donation challenges notions and practices of the body, death, and social relations (Haddow, 2005; Scheper-Hughes and Wacquant, 2003) and how they vary across health-care contexts (e.g. Jensen, 2011 on Denmark and the US; Lock, 2002, on Japan; Vamos, 2010, on aboriginals' beliefs; Das, 2000, on India). Scholarship in the tradition of science and technology studies (STS) brings us closer to a practice-based analytical framework by highlighting the role of objects and artifacts (such as implants) in transplantation medicine (e.g. Hoeyer, 2009; Jensen, 2011). With a stronger focus on human experience, rather than materiality, psychologists and medical sociologists have explored the perspectives of organ recipients and their relatives, how relatives of organ donors assign (arguably more "positive") meaning to the patient's death (Haddow, 2005; Klassen and Klassen, 1996), and why relatives frequently decide not to donate organs for transplants (Sque et al., 2008). However, research that explores the role that these socially informed mechanisms play for clinicians remains rare (however, see Shaw, 2010) and has thus far not informed policymaking. Particularly in the Dutch context, where efforts to increase donation rates have relied on media campaigns and organizational support systems, accounts of professional experiences add insights for research and policy alike. Instead of reproducing contemporary policy discourse by asking merely evaluative questions - that is, how to promote organ donation-in this study, we explore how the socio-technical contingency of organ donation is managed in clinical settings. 
Paul, K.T., Avezaat, C.J.J., Friele, R.D., IJzermans, J.N., Bal, R.A. Organ donation as transition work: policy discourse and clinical practice in The Netherlands. Health:

We draw on two conceptual sources: First, we are inspired by Strauss et al. (1982, 1985), particularly regarding the role of technologies in shaping work in relation to objects that are "alive, sentient, and reactive" (Strauss et al., 1982: 254). Second, we draw on Vaughan's (2005) ethnographic study of air traffic controlling and her concept of "layers of knowledge" (p. 48ff.). "Institutional knowledge” is taught in formalized training and classes where air traffic controllers learn "thousand of bits of information, phraseology, technique and how to use the technology” (Vaughan, 2005: 49). "Local knowledge," on the contrary, is acquired in air traffic facilities, where aspiring air traffic controllers observe senior controllers and "learn by mistake" (Vaughan, 2005). Third, "tacit knowledge" is a more subtle form of knowledge, such as "room awareness" and the ability to interpret, anticipate and coordinate others' actions (Vaughan, 2005; cf. Polanyi, 1983 [1966]). In this study, we use these "layers of knowledge" as analytical labels in studying and classifying the legal, social, organizational, and clinical efforts at managing and coordinating organ donations in clinical settings. Drawing on the sociology of work, organizational sociology, and at the same time grounded in the empirical material collected, we therefore capture organ donation in the term "transition work," encompassing the institutional, sentimental, and technical investments in organ donation.

\section{Methodology}

We conducted a total of 27 interviews across five hospitals in the period of MarchMay 2010 as part of a larger interdisciplinary mixed-methods study (Coppen et al., 2011). Our formal written requests for interviews were assessed and approved by the hospitals' directors; no additional institutional ethics review was required under Dutch regulations. These interviews were conducted in Dutch language, recorded, and subsequently transcribed verbatim (a total of 30 hours of spoken text). A qualitative social science researcher and a retired neurosurgeon conducted all interviews jointly and reported back to the project team at regular intervals. The interdisciplinary nature of the conducted interviews, in which the leading role was explicitly assigned to the social science researcher, promoted "interactional expertise” (Collins and Evans, 2002): As the research project proceeded and social interactions between the social science researcher and medical professionals increased, the researcher became increasingly fluent in the respondents' language. In terms of conversation style, the interviewers had carefully prepared lists of topics and open questions, based on (1) a series of exploratory discussions with the interdisciplinary project group (which included, among others, a surgeon and a transplant coordinator (TC)) and (2) a literature review of existing health services and sociological research identifying current issues regarding organ donation. The hospital sites were chosen on the basis of maximum variance: We selected hospitals of different sizes and profiles ( 1 academic, 2 large, and 2 small) across five provinces. In each hospital, we interviewed four medical professionals who hold key positions regarding organ donation: one intensive care nurse, one intensive care specialist, one neurologist, and the donation coordinator. We also interviewed one member of the board of directors in each hospital, as these tend to play important roles in shaping clinical priorities. ${ }^{2}$

To identify respondents, we initially addressed donation coordinators who referred us to potential respondents. Donation coordinators (donatiecoördinatoren) are installed 
Paul, K.T., Avezaat, C.J.J., Friele, R.D., IJzermans, J.N., Bal, R.A. Organ donation as transition

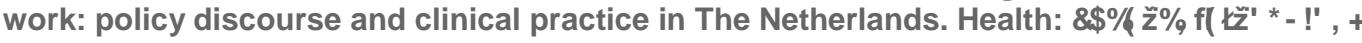

in most general hospitals and are tasked with promoting training and supporting staff in their efforts to increase organ donation rates. We introduced our interviews as preparatory work for a national survey (Coppen et al., 2011), financed by the Ministry of Health. This may have produced a degree of bias, as donation coordinators tended to refer us to more experienced and motivated professionals. To deal with this potential bias, our interviews left considerable room for respondents to bring forward their own concerns, anecdotes, and scenarios. Our analysis is based on multiple readings, using inductive content analysis (Strauss and Corbin, 1998) to identify and categorize professional narratives about their involvement in organ donation practices. Below, we describe and discuss four central themes that emerged as key descriptive labels in the coding process and, in collection, inform our conceptualization of organ donation work as transition work.

\section{ANALYSIS: TRANSITION WORK FROM PATIENT TO DONOR}

\section{The consent request}

Little is known about the micro-politics of consent requests, not least due to the difficulties in accessing these moments empirically. Recent research by the Netherlands Transplant Foundation (Nederlandse Transplantatie stichting, NTS) suggests that approximately 57-62 percent of potential donors are "lost" because of “family refusal” (Jansen et al., 2010) and calls for improved communications skills in order to increase donation rates. Indeed, in our interviews, the consent request conversation with the next of kin is frequently described as the most difficult part in the transition from patient to donor. We propose that it is in this moment that professionals interactively engage in renegotiating what Casper (1998: 36-38) refers to as the "primary work object" in her study of boundary drawing in fetal surgery. In the case of organ donation and transplantation, the professional divisions around what constitutes the "primary work object" (Casper, 1998) gradually shift from the donor-patient to the organ recipient. This shift, however, is not linear or natural, but entails active "transition work" informed by institutional, local (or "organizational"), and "tacit” (or "experiential”) layers of knowledge as well as culturally informed assumptions.

First, the relevance of culturally informed assumptions and experiential knowledge becomes evident in the extent and nature of difficulties reported by professionals. Our respondents report that these difficulties depend on the cause of death and the donor-patient's age, and whether the donor-patient is registered in the National Donor Register or not, as all these factors appear to impact the willingness of the next of kin to agree to organ donation. Second, beyond the donor-patient's characteristics, the ways in which relatives are perceived plays an important role in the consent request. More specifically, our respondents report to be comparatively hesitant to approach Muslim families, guided by the assumption that they may be difficult to confront (NEU-2): Initiating contact with Muslim families is experienced as "a whole different story" (NEU-3). This finding is in line with existing studies on the ways in which medical professionals draw on vague notions of "culture" in diagnostic practices, using them in their "ordering” practices to classify and categorize (Meershoek and Krumeich, 2009: 16), or to account for their (non-) action in particular cases. Refusal to consent by families with a migration background is experienced as different from families of other faiths, and obtaining consent from a 
Muslim family is experienced as "something quite special" (DC-TC1-1) and as a professional success. This socially informed assumption has important implications for patient-donor detection in hospitals, as professionals may hesitate to initiate a consent request when assuming a particular religious background (NEU-2). In this way, socially informed assumptions can gradually turn into organizational (local) knowledge and become a "regular anomaly."

Third, institutional knowledge plays an ambiguous, and arguably less decisive, role in the consent request. There is no coherent protocol on who should be present (beyond the intensivist). Informal professional divisions mark the consent request, reflected particularly in practices of "setting the scene." For instance, a division of roles between the intensivist and the neurologist seems important at an academic hospital (INT-1), but is not always feasible elsewhere: The presence of a neurologist may create some relief for the intensivist, as the latter can still talk about the donor as a patient, which in turn may promote trust on behalf of the relatives. Moreover, there is no formal script as to the presence of a nurse, whose involvement in the consent request appears to depend on organizational practice and identity, for example, as a training hospital, or the notion that nurses may distract from the consent request. Some doctors are concerned that nurses do not sufficiently understand the organ donation process and that they would "color information in ways that doctors wouldn't” (INT-1). In our interviews, specialists explained the lack of active involvement of nurses in the consent request by referring to a lack of expertise in this area (INT-1; INT-4), while the question of "attitude" remains untouched upon in our interviews (see Zambudio et al., 2006, for a pertinent study). In this way, the question of emotions is marginalized, and the donation trajectory is reduced to requiring technical or institutional, rather than experiential, forms of knowledge. Further speaking to this tension between layers of knowledge, a considerable number of respondents highlight the question of which doctor leads the first conversation, their level of experience and seniority (and hence their perceived trustworthiness), and whether he or she is also able to continue the trajectory in order to provide continuity for the patient's family. As two respondents recount,

Those conversations are often led by different people. Everyone does their job perfectly, but they use different words. [...]. And this way, the trust relationship for the family diminishes. (DC-2)

We always try to stay with the family ... because I'm a known face to them, because I remain by the bedside, after all. That way, they get the impression that someone cares ... (NURSE-2)

The concerns expressed by the cited nurses (DC-2; NURSE-2) further emphasize continuity in donor-patient care; in addition, they give expression to the importance of institutional knowledge ("training," "skills," and "doing one’s job correctly”) as well as organizational and tacit knowledge ("continuity," and "trust relationship"). Finally, not only the patient's family, but also the involved professionals draw on the "gift of life" discourse to make sense of the consent request. As a nurse and an intensivist put it, respectively, 
Paul, K.T., Avezaat, C.J.J., Friele, R.D., IJzermans, J.N., Bal, R.A. Organ donation as transition

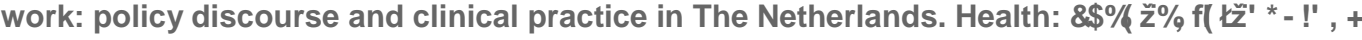

This type of work is different ... you have to think about it a little bit (differently) because you are not actually helping that patient directly, but patients you don't know. (NURSE-5)

I often think: “[otherwise] this person is just dying for nothing.” [...] Personally, it gives me some satisfaction if transplantation does take place eventually. Then I think: at least he is not dying in vain. But, well, perhaps that's my problem. (INT-1)

In this way, medical professionals express the notion that organ donation is a routine, "normal" event to be handled professionally, whereas the ambiguities they may experience are personal problems. This suggests that professionals find it difficult to formulate and express the social and emotional aspects of performing organ donations, as these are seen as their own "problem."

To conclude, the consent request is a key moment in the patient-donor transition, but remains marked by ambiguities regarding divisions of roles, setting the scene, and informal rules of what counts as socially and culturally appropriate. This ambiguity, however, is not only due to differences and uncertainities in consent request protocols (as a form of institutional knowledge). Rather, to account for their (non)agency in the consent request, professionals use a variety of both institutional and socially informed narrative resources, including assumptions regarding ethnicity and the "gift of life" discourse.

\section{Managing ambiguity through protocols: determining brain death}

Protocols have played a central role in stabilizing and institutionalizing the concept of brain death and hence transplantation medicine. Yet, although the Dutch Health Council (Gezondheidsraad) provides a rather firm script regarding the sequence of clinical and technical tests to diagnose brain death (Gezondheidsraad, 2006), several hospitals feltthe need to translate the revisions into local protocols (cf. Van Dijk et al., 2009: 1246). In addition, our study shows that these do not entirely capture the experience of professionals and that the brain death protocol is not exclusively experienced as supportive infrastructure.

The brain death protocol (Gezondheidsraad, 2006) requires confirmation of the clinical diagnosis of brain death by means of an electroencephalogram (EEG) and an apnea test (in this sequence). If these ancillary tests cannot be performed (for technical reasons), completed (apnea test), or reliably interpreted (in instances of barbiturate coma), they must be substituted by transcranial Doppler (TCD) and computerized tomography angiogram (CTA). Our respondents, however, report different understandings of the stipulated sequence, revealing a degree of “interpretive flexibility” (Pinch and Bijker, 1984). For instance, the sequence and technical requirements of a TCD and CTA-necessary in cases where an EEG is impossible- appear unclear to some respondents. In the legal protocol, the terminology moves between "TCD and CTA" and "TCD after CTA," yet nowhere does it indicate that a CTA would be sufficient (see Gezondheidsraad, 2006, paragraph 4.1). These additional diagnostics also involve transportation of donorpatients, which puts them at a higher risk of complications. When a TCD is impossible (for logistical reasons or due to difficulties in finding a proper window), doctors may not proceed to a CTA, leaving them with a non-heart-beating procedure as the sole option. 
Paul, K.T., Avezaat, C.J.J., Friele, R.D., IJzermans, J.N., Bal, R.A. Organ donation as transition

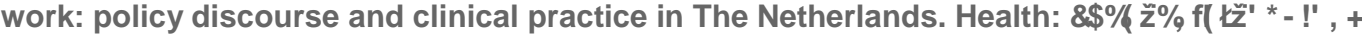

This interpretive flexibility can have important implications: In one reported case, a procedure had to be canceled because the CTA preceded the TCD. In another case, a nurse (NURSE-2) recounts performing an apnea test together with a doctor, having consulted the protocol as to how to perform it, yet only later realized that had not confirmed at what stage to perform it (i.e. after an EEG, as an apnea test bears risks for the donor- patient). The most recent legal revision of the brain death protocol seems to produce additional ambiguities, as an intensivist explains,

[It] hasn't made it easier for the average intensivist (...) I understand that you want to avoid taking out organs without justifying it but, really, we don't want to go over the top with all these diagnostic tools, because for the patient who is lying there, it really does not make a difference: he is dying anyway for sure! (INT-1)

While this doctor refers to institutional knowledge-manifested in material toolsshe also implies being overburdened by the increasing use of technologies and indicates the importance of experiential knowledge, that is, just knowing that the patient will die anyway.

A nurse feels similarly overwhelmed by the change in pace brought about by new technologies and describes this tension between institutional knowledge and experience as follows:

For most people, dying means that your heart stops, and that idea of brain death remains something strange ... rationally, of course, you know that someone is dead when their brain does not function any longer. But still, when they [the surgeons] take him to the OR, I always think: I hope they give him anesthetic before they start ... you never know for sure. (NURSE-2)

Anesthetics would usually not have a place in an organ donation trajectory in the Netherlands (cf. Sharp, 2006 for the US and Jensen, 2011 for Denmark), and the cited nurse knows so, too. Yet by referring to it, the nurse reframes the donor as a patient, thereby managing her ambivalence.

Second, a number of respondents, including intensivists and neurologists admit that they typically first establish imminent brain death, then initiate a consent request with the family, and then order an EEG (INT-1, NEU-3), while aware that the law requires the reverse order. Our understanding is that in this way, clinicians can more clearly identify and define the patient-donor's condition and communicate more effectively with the next of kin. Informal protocols, such as rules of seniority, appear equally important: For instance, an intensivist would usually not let junior doctors perform the clinical tests, but rather "tell them to call their boss" (INT-1). Similarly, several nurse respondents argue for assigning the task to a senior doctor, who may "gain more respect" from the donor-patient's family (NURSE-2). An intensivist (INT-4) further suggests, "The idea of brain death is difficult for a lot of people. They don't have much experience with it.” The reports of these respondents reflect the importance of tacit knowledge ("experience"), rather than only institutional knowledge ("protocols").

A third development experienced as a burden relates to organizational continuity. Nurses as well as specialists express concerns regarding the growing number of residents and interns who gain little experience with donations (DC-2, INT-3, and 
INT-1). Through restructuring of ICUs, nurses have less contact with neurologists, which may impact on the ways in which organ donation is handled and may produce issues of continuity in donor management. "Neurologists seem a bit embarrassed when they come to the ICU ... and then all those beepers and phone calls, they do not have affinity with that [anymore]” (NURSE-2). In this way, the nurse points to the differences in tacit knowledge that involves familiarity with sounds, tools, and ways of speaking, and additionally demarcates brain diagnostic "transition work" from her own "care work,” where she would "often find (herself) in (her) own little world with the patient and their family" (NURSE-2). Notably, nurses provide the most continuity in organ donation cases, as they are typically assigned to a single donor-patient during their shift.

To conclude, these impressions indicate that professionals face ambiguities in placing their own role in organ donation trajectories. Contrary to dominant assumptions in current policy discourse, protocols are also experienced as burdensome rather than merely supportive. In addition, our study highlights the importance of tacit and experiential knowledge in managing ambiguity and that brain death diagnostics are not strictly defined linear routines.

\section{Transition work in ICUs: patient-donor and professional transitions}

Organ donation procedures entail extraordinary logistical efforts, yet ICUs are, by definition, clinical spaces that can accommodate unexpected events. Donation procedures are therefore not necessarily experienced as disruptive in the five hospitals we studied. Instead, our interviews indicate that the ways in which organ donations are embedded and integrated in regular care are of more critical importance than specific logistical bottlenecks. As a donation coordinator observes, “intensivists prefer to cure than to perform organ donations (...) it's not completely normal [and] [specifically non-heart-beating donations] conflict with the ways ICU nurses normally work" (DC-TC2-1), as very little time is available to receive relatives' consent. Similarly, a nurse explains that a heart-beating donor still "looks perfect, also his color" and is still breathing, but "he is simply dead" (NURSE-5). "That remains a strange concept [...]: You know someone has died but you are about to embark on a very time-intensive procedure” (DC-TC1-1; cf. NURSE-5). Put differently, the meaning of the donor-patient's bodily activities (breathing, coloring) as well as the meaning of clinical routine work (keeping a patient stable) are transformed when organ donation is introduced as an option. Individual professionals themselves undergo a transition in their role vis-à-vis the patient: As an intensivist recounts,

I always find it difficult that, on the one hand, as a doctor, you try to make the patient better and then at a given moment, you have to make a kind of switch-“ -OK, I cannot make this patient better anymore but I will now try to keep his organs as stable as possible.” (INT-1)

Similarly, a nurse explains,

It just continues to be difficult that you cause a family so much pain while other families will be very happy. It's that contrast that still feels strange. (NURSE-2) 
To cope with these experienced contradictions, and the professional transition from treating a patient to caring for a potential donor, donation coordinators and nurses we interviewed frequently refer to their patient-donor transition work as "end of life care," and refer to the credo: "donor care means patient care.” This notion seems to help professionals internalize organ donation as a necessity, if not a moral and professional responsibility: "An organ donor is just as important to us as a patient [...]. Patient care means donor care” (DC-2). We specifically found this notion internalized in an academic and a teaching hospital (H1, H2), and the campaign material we reviewed (e.g. NTS, 2013; Transparant, 2009). This speaks to the institutional, training-related significance of this terminology and highlights the ways in which policy travels to practice.

While intensivists were typically more hesitant to engage in more specific patient accounts, nurse respondents alluded to frictions between nurses and doctors, as nurses may be skeptical of life-prolonging measures, such as cerebral ventricular drainage to relieve intracranial pressure, that potentially create too much hope with the patient's family (cf. INT-2). More concerned about the donor-patient's “quality of life," a nurse explains "[I often think:] just let him die because he'll still be better off than ending up in a nursing home" (NURSE-2). At the same time, professionals internalize death as a "normal" part of their job in intensive care: "We see so many people die and from the very beginning you are expected to learn how to deal with that. I guess you just have to-it's that or quitting altogether" (NURSE-2).

This material indicates that the transition from treating a donor-patient to curing the "invisible” patient (i.e. the potential organ recipient) is not clear-cut, as protocols would suggest, but it entails active, complex, and iterative transition work, including managing one's emotions. The institutional layer of knowledge, however, is assigned a predominant role in the overall policy discourse, reflected in the frequent suggestion that organ donation rates could be increased through logistical improvements. In our interviews, conversely, we find interesting discrepancies in our respondents' representation of the role of logistics in performing and completing organ donation. On the one hand, respondents reproduce policy discourse by frequently alluding to difficulties in securing the necessary logistical infrastructure, both in large and small hospitals. On the other hand, when asked for specifics or concrete examples, we rarely found pertinent detailed information, but instead an insistence that "we absolutely miss no donors" (DC-2; HD-1). While this could signal reluctance of clinicians to discuss mistakes or procedural breakdowns, we suspect that although logistical problems do occur in the donor procedure, these are dealt with in an ad hoc fashion, as is typical for emergency and intensive care. The introduction of facilitating tools, such as organizational charts, donation kits, and documentation of initiated organ transplantation procedures, has also been a byproduct of the assumption in policy discourse that logistical improvements are at the core of tackling "organ shortage" and facilitating both patient-donor transitions and professional transitions. For instance, a donation coordinator reports that on the occasion of a potential donation, her ICU colleagues dutifully consulted the newly purchased “donation kit” containing a number of tools to facilitate donation. Only later, and following a number of "panicked phone calls" (DC-5), it appeared that this kit was reserved for non-heart-beating donations and was hence of little use for a regular organ donation. Similarly, a recent investment in new ventilation machines in one of the hospitals we visited (H5) has interfered with experiential layers of 
knowledge, as professionals experience difficulties performing an apnea test due to its inbuilt backup function. This highlights the ambiguous and multiple functions of medical technologies in this context: on the one hand, they are required to keep patients alive, while on the other hand, they need to be shut off to determine whether the donor-patient has passed away. Moreover, it is interesting to note that backup functions as manifestations of a growing patient safety discourse in health care, in this context, seem to interfere with the discourse of increasing organ donation rates. To conclude, while advances in transplantation medicine have relied on institutional layers of knowledge and the related development of a number of suitable technologies, they also help sustain and reproduce the construct of an "organ shortage." At the same time, institutional knowledge promotion ("training," “donation kits," "logistics," and "patient safety”) will not always match its intentions when other forms of knowledge are left unconsidered.

\section{Evaluation, paperwork and feedback mechanisms}

As part of the current policy discourse toward improving efficiency, efforts have been directed at improving logistical capacities in hospitals. The NTS, established through the Organ Donation Act in 1998, has developed a tightly knit network where so-called donation coordinators (formerly known as donatiefunctionarissen, currently donatiecoördinatoren) are installed in most general hospitals, a regional team leader and supervisor at the regional academic hospital support them, and transplant centers employ TCs. Likewise, the medical records analysis (Medisch Status Onderzoek, MSO) developed by the NTS helps keep track of both potential and effected organ donations. The function of this digital tool appears intimately connected to the specific monitoring role of donation coordinators in organizational networks.

Donation coordinators usually do not undergo specific training and their position varies, that is, the hours they spend on this function, their background (e.g. as an ICU nurse), and their networks within the hospital. They do not, however, get involved when a potential donation trajectory is initiated. In addition, as mentioned earlier, donation coordinators frequently conduct this part of their work in office-ial settings that are not only physically remote but also removed in terms of daily experience. The position of donation coordinators is premised on the very notion of an "organ shortage" and concerns about "missing donors" as expressed in the current policy discourse and research agenda. At the same time, their working practices reproduce the notion that organ donation rates can be improved through technocratic fixes such as forms, records, and paperwork, rather than, for instance, qualitative feedback. More specifically, the aforementioned MSO is intended as a step toward recording hospitals' adherence to (tissue and organ) donation policy and assessing actual donor potential. Donation coordinators fill in a digital form, based on doctors' reports, in order to help assess whether the deceased patient could have been a potential donor. In turn, this tool also presents an instrument to assess and trace the performance of individual medical professionals regarding organ donation, for example, the rate of consent requests and procedures completed.

This is typically performed by TCs or donation coordinators on the basis of a donation form (donatie applicatie), which has to be filled in for every death by doctors, and is subsequently translated in a digital form. As the aim was to design the form in a way that is efficient and not too time-consuming for doctors, there seems to 
Paul, K.T., Avezaat, C.J.J., Friele, R.D., IJzermans, J.N., Bal, R.A. Organ donation as transition

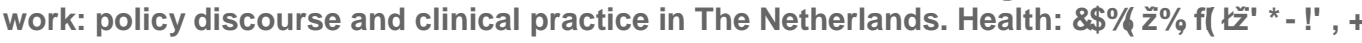

be inadequate room for qualitative explanation, for example, why a family objected. Donation coordinators usually check these forms and report back to doctors if they feel that they may have been filled in incorrectly or in too much of a hurry. An informal half-day observation of a donation coordinator's work in a large urban hospital (H3) also revealed that donation coordinators engage in a "translation" of doctors' notes, having to judge the accuracy of the information entered by doctors and "what they meant." We suggest that while donation coordinators and their use of donation forms are intended to make errors visible, this act of translation may ultimately produce the opposite. In other words, evaluation processes may function as an organizational ritual, rather than producing a learning effect. In this way, errors, such as failure to detect donors, may become a "normalized" feature of organizations, which may have important implications for donation rates (cf. Bolsin et al., 2005 for an informative discussion on recording near misses and errors in clinical practice).

\section{CONCLUSION}

In the Netherlands, the dominant notion of the current "organ shortage" as a "public health crisis" has largely remained unquestioned in policy discourse and facilitating organ donation is frequently presented as an ethical, social, and medical necessity. Accordingly, research and policy proposals that address this issue often focus on economic evaluations and assessment of logistical improvements, emphasizing the need for increased efficiency and encouraging choice in the central donor register. In this study, we focused on how professionals experience organ donation and inquired: What kind of work and knowledge does organ donation entail and how does this work relate to contemporary policy discourse?

\section{Empirical findings}

Our empirical findings concern the relation between contemporary policy discourse and the "realities" of clinical practice. We find that notwithstanding legislation and clinical protocols, organ donation policy discourse is dynamic and contested. The underlying expectation in this policy discourse is that medical professionals either possess or should learn the practical skills necessary for successful transplantations of organs, following clinical guidelines that specify the donation process. To explore the actual practice of and experience with organ donation, we conducted in-depth interviews with medical professionals. By way of multiple readings of our qualitative data and note-taking throughout the research process, we inductively derived four labels, discussed here as "themes." Grounded in these descriptive labels, we have conceptualized organ donation as "transition work" whereby a patient becomes a donor and through which organ donation becomes reproduced, but also contested, as an organizational and moral imperative. First, the consent request is shaped by tacit understandings of seniority in the division of tasks, as well as socioculturally informed categorizations in (not) approaching the families of potential donors. Second, brain death diagnostics are not strictly linear but marked by interpretive flexibility and ambiguity; particularly the sequence of stipulated tests is experienced as unclear and burdensome by some of our respondents. Third, the controversial nature of transition work becomes particularly visible in ICUs, where professionals themselves struggle to redefine the meaning of their work in relation to the transition 
from patient to donor. Fourth, and contrary to the frequent allusions to the need for technical and logistical improvements to promote organ donation in policy discourse, our respondents did not refer to logistical problems as key factors contributing to “organ shortage.” Indeed, we find that evaluation and feedback mechanisms may take on the character of organizational rituals, and do not provide an outlet for expressing ambiguity at the level of professionals' experiences with organ donation. Rather, the administrative work taken on by donation coordinators reflects and reproduces the predominantly technocratic assumptions evident in policy discourse.

\section{Conceptual discussion and methodological reflections}

The empirical findings indicate that "transition work" entails technical tinkering, finding ad hoc logistic solutions, and engaging with families and managing one's emotions. At the same time, the four identified themes point to the "mismatch" between policies and clinical practices. We conceptualize this discrepancy by drawing on Vaughan's (2005) study of air traffic controllers that points to the mismatch between institutional, organizational (or "local"), and tacit (or “experiential”) knowledge. As discussed above, tacit knowledge is a more subtle form of knowledge, such as the ability to interpret, anticipate, and coordinate others' actions (Vaughan, 2005). This form of knowledge, in which the role of emotions can also be placed, remains insufficiently considered in current policy discourse that focuses on "logistical bottlenecks." The ambiguous nature of organ donation as "transition work," we propose, escapes protocolization and formalization and entails organizational and tacit layers of knowledge. While protocols remain important, engaging in transition work means tinkering with existing resources, thus eluding the central emphasis on standardization. To conclude, the conceptual resources borrowed from the sociology of work (Strauss et al., 1982) and organizational studies (Vaughan, 2005) may help redirect policy discourse away from "how can we improve organ donation” and toward asking: What are existing ways of doing transition work and how can those be understood? Thus, rather than infusing organ donation practices with more protocols and organizational interventions, practices of “exnovation” (Mesman, 2011) could be strengthened.

As an additional contribution, this study demonstrates the usefulness of interdisciplinary interviewing, which is rarely reported and comes with advantages and specific challenges. Working with a neurosurgeon lent nearly immediate credibility and legitimacy to the interview situation, while in some cases, his presence may have been perceived as an implicit expression of blame, that is, suggesting that the respective hospitals needed "help" from a senior colleague. Moreover, our study was strongly guided by the explicit task assigned by the Ministry of Health to "identify bottlenecks" with respect to organ donation. This assignment, in a sense, also formed our primary stumbling block: After a first round of interviews, it became increasingly clear that asking respondents about "bottlenecks," that is, technical problems, would not enable us to help respondents develop their stories in a fashion useful for sociological research. In addition, a certain "clash of interviewing cultures" seemed inevitable, entailing the need for a compromise between anamnesis-style and openended interviews, which focus less on, for example, the frequency of specific diagnostic exams, but rather, what it means for professionals. Ethnographic observations might have added in-depth insight, for example regarding the role of organizational rituals (cf. Jensen, 2011), but were not feasible in this study. 
Paul, K.T., Avezaat, C.J.J., Friele, R.D., IJzermans, J.N., Bal, R.A. Organ donation as transition

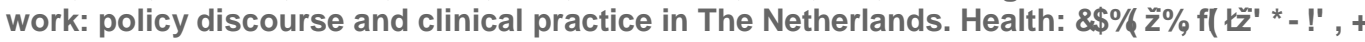

In current mechanisms used to promote organ donation in hospitals, policy discourse largely draws on institutional knowledge ("developing skills," "formulating guidelines and checklists,” and "facilitating logistical support”). Conversely, our study of the experienced ambiguities pertaining to organ donation policy leads us to question some of the assumptions made in those mechanisms: that organ donation is a "normal" procedure consisting of clear-cut steps, and that the underlying tools, such as brain death diagnostics are regular and unambiguous tasks. For as this qualitative study indicates, brain death diagnostics and organ donation procedures are indeed marked by social as well as technical ambiguities.

\section{Acknowledgements}

The authors would like to thank Hanneke Hagenaars (Erasmus Medical Center) and Remco Coppen (NIVEL) for their support and feedback as members of the project team. The corresponding author was involved in this study during her appointment as assistant professor at Erasmus University Rotterdam (iBMG). An earlier version of this paper was presented at the 6th International Conference in Interpretive Policy Analysis in Cardiff, UK; we would like to thank Herbert Gottweis for his comments in that context. In addition, the paper benefitted greatly from the insightful comments of Hester van de Bovenkamp and colleagues at the Institute of Health Policy \& Management.

\section{Funding}

This study was supported by grant no. 316941 by the Ministry of Health, Sport, and Welfare (Ministerie van Volksgezondheid, Welzijn en Sport) in the period of 1 January 2010 to 31 December 2010 as part of the Ministry's Masterplan Organ Donation.

\section{Notes}

1. We focus on heart-beating organ donation. Non-heart-beating donations entail very specific ethical, legal, and clinical challenges, which we were unable to consider in-depth in this study.

2. To guarantee anonymity, throughout this article, we apply the following respondent codes: Hospital codes-1: academic, 2: large, 3: large, 4: small, 5: small; respondent codes-INT: intensive care specialist, NURSE: Nurse, NEU: Neurologist, DC: donation coordinator, HD: hospital director, DC-TC: donation coordinator in the position of transplantation coordinator. A nurse in hospital 1, for example, appears cited as NURSE-1. In hospital 1, we interviewed two donation officers who hold positions as transplantation coordinators. These appear cited as DC-TC1-1 and DC-TC2-1, respectively. In hospital 5, a second intensive care specialist offered to speak with us, resulting in 27 interviews in total.

\section{REFERENCES}

Boas H (2011) Trends of generalized and restricted altruism in organ donations. Social Science \& Medicine 73(9): 1378-1385.

Bolsin S, Faunce T and Oakley J (2005) Practical virtue ethics: Healthcare whistleblowing and portable digital technology. Journal of Medical Ethics 31: 612-618.

Casper M (1998) Working on and around human fetuses: The contested domain of fetal surgery. In: Berg M and Mol A (eds) Differences in Medicine: Unraveling Practices, Techniques, and Bodies. Durham, NC: Duke University Press, pp. 28-54. 
Paul, K.T., Avezaat, C.J.J., Friele, R.D., IJzermans, J.N., Bal, R.A. Organ donation as transition

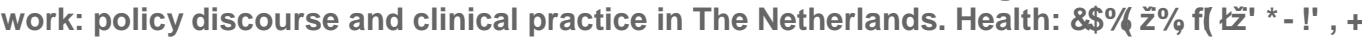

Collins HM and Evans R (2002) The third wave of science studies: Studies of expertise and experience. Social Studies of Science 32(2): 235-296.

Coordinatie Groep Orgaandonatie (2008) Masterplan orgaan donatie: de vrijblijvendheid voorbij. The Hague: Coordination Group Organ Donation.

Coppen R, Friele RD, Gevers SKM, et al. (2010) Donor education campaigns since the introduction of the Dutch organ donation act: Increased cohesion between campaigns has paid off. Transplant International 23(12): 1239-1246.

Coppen R, Friele RD, Marquet RL, et al. (2005) Opting-out systems: No guarantee for higher donation rates. Transplant International 18(11): 1275-1279.

Coppen R, Paul KT, Avezaat CC, et al. (2011) Praktijken van orgaandonatie in Nederlandse ziekenhuizen, een studie in het kader van het Masterplan Orgaandonatie [Organ donation practices in Dutch hospitals: A study in the context of the Masterplan on Organ Donation]. Utrecht/ Rotterdam: NIVEL, Erasmus University Rotterdam.

Das V (2000) The practice of organ transplants: Networks, documents, translations. In: Lock $\mathrm{M}$, Young A and Cambrosio A (eds) Living and Working with the New Medical Technologies: Intersections of Inquiry. Cambridge: Cambridge University Press, pp. 263287.

Delmonico FL, Arnold R, Scheper-Hughes N, et al. (2002) Ethical incentives—not paymentfor organ donation. New England Journal of Medicine 346(25): 2002-2005.

DelVecchio Good MJ, Gadmer NM, Ruopp P, et al. (2004) Narrative nuances on good and bad deaths: Internists' tales from high-technology workplaces. Social Science \& Medicine 58(5): 939-953.

Gezondheidsraad (2006) Hersendoodprotocol. The Hague: Gezondheidsraad (Netherlands Health Council).

Glaser BG and Strauss AL (1968) A Time for Dying. Chicago, IL: Aldine.

Hadders $\mathrm{H}$ (2009) Enacting death in the intensive care unit: Medical technology and the multiple ontologies of death. Health 13(6): 571-587.

Haddow G (2005) The phenomenology of death, embodiment and organ transplantation. Sociology of Health \& IIIness 27(1): 92-113.

Healy K (2004) Altruism as an organizational problem: The case of organ procurement. American Sociological Review 69(3): 387-404.

Healy K (2006) Last Best Gift. Chicago, IL: Chicago University Press.

Hoeyer K (2009) Tradable body parts? How bone and recycled prosthetic devices acquire a price without forming a 'Market'. Biosocieties 4: 239-256.

Hoeyer K and Jensen AMB (2011) Organ donation and the ethics of muddling through. Critical Care 15: 109.

Jansen NE, van Leiden HA, Haase-Kromwijk BJJM, et al. (2010) Organ donation performance in the Netherlands 2005-08; medical record review in 64 hospitals. Nephrology Dialysis Transplantation 25(6): 1992-1997.

Jensen AMB (2011) Searching for meaningful aftermaths: Donor family experiences and expressions in New York and Denmark. Sites: A Journal of Social Anthropology and Cultural Studies 8(1): 129-148.

Kellehear A (2008) Dying as a social relationship: A sociological review of debates on the determination of death. Social Science \& Medicine 66(7): 1533-1544.

Klassen AC and Klassen DK (1996) Who are the donors in organ donation? The family's perspective in mandated choice. Annals of Internal Medicine 125(1): 70-73.

Lock M (2002) Twice Dead: Organ Transplants and the Reinvention of Death. Los Angeles, CA; Berkeley, CA: University of California Press.

Lupton D (2003) Medicine as Culture : Illness, Disease and the Body. London: SAGE.

Mauss M (1990) The Gift: The Form and Reason for Exchange in Archaic Societies. New York: WW Norton.

Meershoek A and Krumeich A (2009) Multiculturalism and the construction of ethnic identities in labour and health practices: Avoiding the culturalistic fallacy in applied research. Health Care Analysis 17(3): 173-197.

Mesman J (2011) Resources of strength: An exnovation of hidden competencies to preserve patient safety. In: Rowley E and Waring J (eds) A Socio-cultural Perspective on Patient Safety. Surrey, London: Ashgate, pp. 71-94. 
Paul, K.T., Avezaat, C.J.J., Friele, R.D., IJzermans, J.N., Bal, R.A. Organ donation as transition

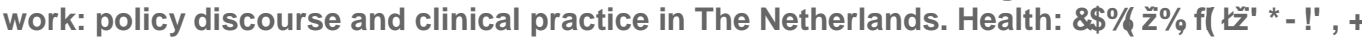

Nederlandse Transplantatie stichting (NTS) (2013) Herstructurering. Available at: www.transplantatiestichting.nl/professionals/herstructurering (accessed 26 April 2013).

Nuffield Council on Bioethics (2011) Human bodies: donation for medicine and research. London: Nuffield Council on Bioethics.

Pinch TJ and Bijker WE (1984) The social construction of facts and artefacts: Or how the sociology of science and the sociology of technology might benefit each other. Social Studies of Science 14(August): 399-441.

Polanyi M (1983 [1966]) The Tacit Dimension. Gloucester, MA: Doubleday \& Co (Reprinted: Peter Smith).

Prainsack B and Buyx A (2011) Solidarity: Reflections on an emerging concept in bioethics. London: Nuffield Council of Bioethics. Available at: http://www.nuffieldbioethics.org/solidarity (accessed 18 January 2012).

Rix BA (1990) Danish ethics council rejects brain stem death as the criterion of death. Journal of Medical Ethics 16: 5-7.

Scheper-Hughes N and Wacquant L (2003) Commodifying Bodies. London: SAGE.

Schrift AD (1997) The Logic of the Gift: Toward an Ethic of Generosity. New York:

Routledge.

Seale CF (1998) Constructing Death: The Sociology of Dying and Bereavement. Cambridge: Cambridge University Press.

Sharp LA (2006) Strange Harvest: Organ Transplants, Denatured Bodies, and the Transformed Self. Berkeley, CA: University of California Press.

Shaw R (2010) Perceptions of the gift relationship in organ and tissue donation: Views of intensivists and donor and recipient coordinators. Social Science \& Medicine 70(4): 609615.

Sque M, Long T, Payne S, et al. (2008) Why relatives do not donate organs for transplants: "sacrifice" or "gift of life?" Journal of Advanced Nursing 61(2): 134-144.

Strauss A and Corbin J (1998) Basics of Qualitative Research: Techniques and Procedures for Developing Grounded Theory. London: SAGE.

Strauss A, Fagerhaugh S, Suczek B, et al. (1982) Sentimental work in the technologized hospital. Sociology of Health \& IIIness 4(3): 254-278.

Strauss A, Fagerhaugh S, Suczek B, et al. (1985) The Social Organization of Medical Work. Chicago, IL: University of Chicago Press.

Streat S (2004) Clinical review: Moral assumptions and the process of organ donation in the intensive care unit. Critical Care 8: 382-388.

Swierstra T, van de Bovenkamp H and Trappenburg M (2010) Forging a fit between technology and morality: The Dutch debate on organ transplants. Technology in Society 32(1): 55-64.

Timmermans S (2005) Death brokering: Constructing culturally appropriate deaths. Sociology of Health \& IIIness 27(7): 993-1013.

Timmermans S and Berg M (2003) The practice of medical technology. Sociology of Health \& IIIness 25(Silver Anniversary Issue): 97-114.

Titmuss RM (1970) The Gift Relationship: From Human Blood to Social Policy. London: George Allen and Unwin.

Transparant (2009) Transparant Nieuwsmagazine van de NTS, Vol. 40, April 2009. Leiden: Nederlandse Transplantatiestichting.

Vamos M (2010) Organ transplantation and magical thinking. Australian and New Zealand Journal of Psychiatry 44(10): 883-887.

Van Dijk JG, Lammers J and Engberts DP (2009) De dood van het brein. Argumenten voor een eenvoudiger protocol bij hersendood. Medisch Contact 64(28): 1246-1249.

Vaughan D (2005) Organizational rituals of risk and error. In: Hutter B and Power M (eds) Organizational Encounters with Risk. Cambridge: Cambridge University Press, pp. 33-66.

Waldby C and Mitchell R (2006) Tissue Economies: Blood, Organs, and Cell Lines in Late Capitalism. Durham, NC and London: Duke University Press.

Wight JP (1991) Ethics, commerce, and kidneys. BMJ 303(6794): 110.

Wijdicks EFM (2002) Brain death worldwide: Accepted fact but no global consensus in diagnostic criteria. Neurology 58: 20-25. 
Paul, K.T., Avezaat, C.J.J., Friele, R.D., IJzermans, J.N., Bal, R.A. Organ donation as transition work: policy discourse and clinical practice in The Netherlands. Health:

Zambudio AR, Conesa C, Ramírez P, et al. (2006) What is the attitude of hospital transplantrelated personnel toward donation? Journal of Heart and Lung Transplantation 25(8): 972976.

\section{AUTHOR BIOGRAPHIES}

Katharina T Paul holds a Lise Meitner Fellowship at the University of Vienna (Life-ScienceGovernance Research Platform). She is currently researching cervical cancer prevention policies in a project funded by the Austrian Science Fund (FWF). She holds a PhD in political science and was previously assistant professor at Erasmus University Rotterdam (Institute of Health Policy \& Management, iBMG).

Cees $\mathrm{JJ}$ Avezaat is a retired neurosurgeon and independent consultant at Erasmus Medical Center in Rotterdam, the Netherlands. Next to his clinical work at the Department of Neurosurgery at Erasmus Medical Center, he has published widely in the areas of neurosurgery and neurology.

Roland D Friele is deputy director and head of research at the Netherlands Institute for Health Services Research (NIVEL), as well as head of the Centre of Knowledge Exchange (CKE). He is also part-time professor of the social impact of health law at Tilburg University. He has published widely in the areas of health law evaluation, health care governance, and health care innovation.

Jan $\mathrm{N}$ IJzermans is professor of organ transplantation and director of the surgical training program at Erasmus Medical Center. In his areas of expertise, organ transplantation, hepatobiliary surgery, robotic surgery, and oncological and transplantation research, he has contributed to more than 300 peer-reviewed articles and book chapters.

Roland A Bal is professor of health care governance and department chair at the Institute of Health Policy \& Management (iBMG) at Erasmus University Rotterdam. His research interests include science, policy and the law, as well as governance infrastructures in health care. 